\title{
Effects of Family Characteristics on the Labor Force Status of Older Married Women in Finland
}

\author{
MARIE REIJO-RISKILÄ \\ Academy of Finland \\ Department of Sociology, Population Research Unit \\ University of Helsinki \\ Helsinki, Finland
}

\begin{abstract}
Using individual-level characteristics derived from the census of 1985 or earlier, the article examines labor force status (employment, unemployment, household work, retirement) of married Finnish women aged 45-64 on the basis of multinomial logit analysis. Controlling for background characteristics, i.e., age, education, health, industry and unemployment in the local labor market area, the effects of family characteristics were analyzed.

Both higher family net income (excluding the income of the women concerned) and higher family liabilities were related to lower likelihoods of unemployment and retirement instead of employment. Household work was more likely with higher family income, but less likely with higher liabilities. A larger number of children living at home was related to the lower likelihood of women occupying non-employment statuses instead of employment. The spouses' increasing age difference was related to the lower likelihood of unemployment and retirement instead of employment. The husband's labor force status was consistent with the wife's labor force status.
\end{abstract}

Keywords: labor force status, older women, family characteristics, Finland

\section{Background}

In the work-leisure framework of neoclassical models economic conditions, i.e., rewards from work, other income, and wealth have been principal individual level incentives of labor supply choice. Other factors related to economic incentives for labor supply and work-leisure oriented preferences are human capital factors (Mincer and Polachek 1974) and among aging population, in particular, such specific late life characteristics as weakening health status (Baily 1987; Sammartino 1987). In addition, among older married women factors affecting the labor supply which have been explored are earlier investments in family and work and current family characteristics, for instance, the effects of the number of dependants and the labor force status of the husband, and work characteristics. Late-life events which have been examined have related to changes in these characteristics. (Clark et al. 1980; Henkens and Siegers 1991; Henkens et al. 1993; Henretta and Rand 1980; Henretta et al. 1993; Pienta et al. 1994; 
Sweet 1973.) Although there has been quite extensive research into the labor supply of Finnish married women (e.g. Ilmakunnas and Lahdenperä 1986; Ingberg et al. 1986) the older women have been very much neglected.

The aim of this research is to analyze a number of labor force statuses: employment, unemployment, household work, and retirement in relation to family characteristics of Finnish married women aged 45-64 in 1985 in local labor market areas, when particular individual demographic background and contextual labor market characteristics have been controlled for. In the age group 45-64 the comparatively high level of employment starts to decline, gathering pace with increasing period age because of the growing tendency of early retirement before the usual old pension age of 65 . In addition to retirement, long-term unemployment and household work are also becoming more common non-employment statuses as period age increases.

This research emphasizes the effects of some family characteristics which relate older married women to different family phases: How does labor force status depend on the family's financial conditions, the presence of children, the age and the labor force status of the husband? The assumptions of these effects will be presented later in this article.

\section{Data, variables and statistical methods}

\section{Data}

The study is based on an individual-level data set which covers the 1985 census records on the whole population of Finland aged 45-64 (persons resident in Finland on a permanent basis on 17 November 1985). Additional data were compiled by linking data from the 1980,1975 , or 1970 census, information about personal taxation and education and all death records for the years 1986-1991. The census data were obtained from administrative registers or were collected using a questionnaire. The data sources for the census included the central population register, the register on deaths, the register on completed education and degrees (all maintained by Central Statistics) and the taxation register (maintained by the National Board of Taxation). The original compilation of the data set was done by Central Statistics. ${ }^{1}$

The data came from 39 local labor market areas (Reijo and Valkonen 1993) and the analysis was restricted to female residents whose labor force status was known during the census week (11-17 November) in 1985. The group of students, women on widowed pensions and others with undefined or unknown labor force status (totaling about $2.2 \%$ in the age group $45-54$ and $3.7 \%$ in the age group 55-64) were excluded from the research. The number of married women aged 45-54 was about 122,000 and those aged 55-64 about 98,000.

\section{Variables}

Following the classification of the population by type of current activity which is used by Central Statistics of Finland (1990), four labor force statuses were distinguished for the purposes of the empirical analysis: employed and the non-employed statuses of unemployed, household workers and retired (retired from work and retired because of disability or for other reasons). Moreover, the data allowed identification of those

' Note: Permission to use the data was granted by Central Statistics, Finland (TK 53-1856-92) 
retired women who received an unemployment pension in the population aged 55-64. After the specific long-term period unemployed persons were eligible for pensions, and in unemployment pensions they were still obliged to work, if it had been supplied by labor force officers. Partly therefore, the unemployed and those women who were retired on unemployment pension were combined in the age group 55-64. The majority of the women of this combined group (over 70\%) were retired on unemployment pensions.

Explanatory individual-level variables of labor force status can be categorized according to an individual's demographic background characteristics, contextual labor market characteristics, and family characteristics.

Demographic background variables were age, educational level, and health status. Women aged 45-54 and 55-64 were analyzed separately, since women in the latter group have lower employment levels and are eligible for more retirement schemes, unemployment pensions, for example. The age variable was classified further in fiveyear age groups among those aged 45-54, and in to two-year age groups among those aged 55-64 to consider the more marked changes in labor force status of women in older ages. Educational level was used primarily as a general proxy for individual opportunities in labor markets, more specifically for expected income. Six categories of educational level were distinguished. The basic level (which was used as a reference group) comprises about nine years of education or less. The lower intermediate level comprises from ten to eleven, the higher intermediate level about twelve, the lowest upper level from thirteen to fourteen, the lower academic level about fifteen, and the higher academic level about sixteen or more years of education. Individual-level mortality from diseases during 1986-91 was used as a proxy of poor health status or biomedical morbidity which is assumed to be a relatively strong constraint on employment, also indicating economic disutility for work. Thus, if a woman died during 19861991, her health status in 1985 was classified as poorer, otherwise as better (reference group). Mortality from suicides, homicides, and accidents was omitted because none of these are related to any specific illness.

Contextual labor market variables related a woman to the state of the labor market in a given area and further within the area to a particular achieved position of labor markets. The total unemployment rate of a women's local labor market area in 1984 was used as a contextual level measure of the state of an area's labor market. The industrial sector of a woman indicated an achieved labor market position and relating structural context for employment. Information about the industrial sector was based on the census data of 1985 providing that a woman was employed. Otherwise, the most recent information either from the census of 1980,1975, or 1970 was used, if a woman was in the labor force. The industrial sector consisted of seven classes: 1) processing (manufacturing, mining and quarrying, electricity, gas and water and construction were combined) (the reference group), 2) wholesale and retail trade, hotels and restaurants, 3) transport, storage, and communications, 4) finance, insurance, real estates and business services, 5) public, social, and personal services, 6) agriculture, forestry, fishing and hunting and 7) no industry, i.e., the persons about whom information was missing. The proportion of married women about whom no information about industry was available (class 7), but who were still classified by labor force status in 1985 was 6 percent among those aged $45-54$ and 18 percent among those aged $55-64$. The majority of these women were doing household work in 1985, as they were during the earlier censuses.

In the category of family characteristics, a set of family financial variables, the number of children, the age difference between the spouses, and the labor force status of the husband in 1985 were examined. The analysis took in other net family income (the logarithm of FIM), referring to the total taxed income of family members after 
the total taxed income of a woman had been subtracted. Other net family income consisted of income from wages, income from a private business and income from property. In addition, housing-related and other family liabilities (the logarithm of FIM) were included in the analysis. Further, the number of children living at home was included; census data were not included on all children a woman had given birth to. Three categories were distinguished: 0 (reference group), 1,2 or more children living at home. The age of the youngest child was also included but omitted from further analysis because of its relatively strong positive association with the number of children. The husband's labor force status comprised four classes: employed (reference group), unemployed, retired and retired on unemployment pension. Others, i.e. women, whose husbands had unknown labor force status (about $0.9 \%$ ) were excluded from the final analysis. Finally, the age difference between the spouses (husband's age minus wife's age) was included as an explanatory variable.

\section{Statistical methods}

Labor force status of women by each individual characteristic was examined first on the basis of cross-tabulations. Second, controlling for other variables, the effects of family characteristics on labor force status were estimated on the basis of multinomial logit analysis (e.g. Fienberg 1989; McCullach and Nelder 1989).

In multinomial logit analysis the response $\mathrm{Y}_{\mathrm{i}}$ in which ${ }_{i}$ refers to individual ${ }_{i}$, is assumed to have one of several discrete values, $1,2, \ldots$, J. The probability that the response will take the $\mathrm{jth}$ value, can be defined by $\pi_{\mathrm{ij}}=\mathrm{PR}\left\{\mathrm{Y}_{\mathrm{i}}=\mathrm{j}\right\}$ with $\sum_{i=1} \pi_{\mathrm{ij}}=1$. The effects of independent variables are evaluated on the log-odds of having one or another of the response categories in relation to the baseline category. When the baseline category is the last one, $\mathbf{J}$, the multinomial logit model can be presented in the following formula:

$$
\log \left(\pi_{i j}\right) / \log \left(\pi_{i j}\right)=\alpha_{j}+x_{i j}^{\prime} \beta_{j}
$$

for $\mathrm{j}=1, \ldots, \mathrm{J}-1$. X describes a vector of independent variables. The maximum likelihood method was used for estimating the parameters, and chi-square tests (Wald statistics) based on the estimated standard errors were used to test the hypotheses that parameters for independent variables are equal to zero. Estimations were carried out by using SAS program and its CATMOD procedure (SAS/STAT User's Guide 1992). In addition to log-odds, original logit-coefficients were shown in the main models.

\section{Results}

\section{Labor force status rates and the effects of background characteristics on labor force} status

Labor force status rates, the proportion of employed, unemployed, household workers, and the retired among married women aged $45-64$ by one-year age groups are presented in Figure 1. Among married women aged 45-49 88.3 percent were employed, among those aged 55-56 62.3 percent and among those aged 63-64 16.0 percent. Among those aged 54 and over retirement was the most common non-employment status.

Next, unemployment, household work and retirement statuses were analyzed in relation to employment status according to all the background variables. The multino- 
F i g u r e 1. Labor force status rates: the proportion (\%) of employed, unemployed, household workers and retired among Finnish married women aged 4564 by one-year age groups in local labor market areas in 1985.

Note: The unemployed and those retired on unemployment pension are separated in the age group 55-64

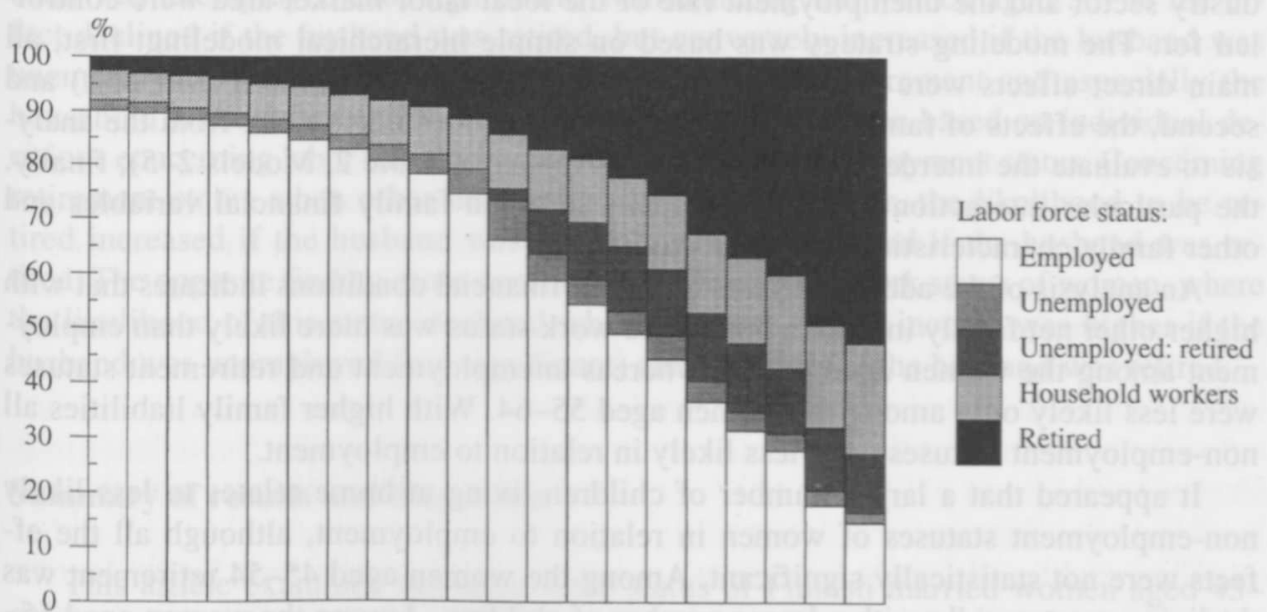

$4546474849505152535455565758596061 \quad 6263 \quad 64$

Age

mial logit models of Appendix Table 1 show the results of the effects for married women aged 45-54 and 55-64 separately.

Reviewing the effects of demographic background variables first, older women especially after the age of 55 , less educated women and women with poorer health status were more likely to occupy a non-employment status than an employment status. Regarding household work status in relation to employment, educational level was an exception: the likelihood of women with a higher intermediate level education having household work status was higher than likelihood of lower educated women. The poorer health status of women aged 55-64 did not have any effect on either more likely unemployment or on more likely household work.

The effects of contextual labor market variables show next, that women whose most recent industry sector was processing, trade or agriculture were most likely to have non-employment status in relation to employment; among those aged 55-64 unemployment focused clearly on women in processing and trade, whereas in agriculture unemployment was not so likely. Instead a household work status was a more likely status in agriculture than in other industry sectors. High employment characterized women who had worked most recently in services, finance and transportation. Furthermore, the higher unemployment was in the local labor market area, the more likely it was that women had a non-employment status rather than employment.

Regarding family characteristics, a smaller number of children, the higher age difference between the spouses, and a non-employment status of the husband were related to a more likely non-employment status of women in relation to employment. Concerning family financial charateristics, lower other net family income was related to more dikely unemployment and retirement status, higher family liabilities were also related to a more likely household work status. These effects are reported in more detail in the following sections. 


\section{Effects of family characteristics on labor force status}

The results of the multinomial logit model in Appendix Table 2 present the logit effects of family characteristics on the unemployment, household work and retirement status likelihoods in relation to employment. Age, educational level, health status, industry sector and the unemployment rate of the local labor market area were controlled for. The modeling strategy was based on simple hierarchical modeling: first, all main direct effects were included in the analysis (Appendix Table 2: Model 1) and second, the effects of family characteristics were reduced one by one from the analysis to evaluate the interdependency of them (Appendix Table 2, Models 2-5); finally, the particular interaction effects, principally between family financial variables and other family characteristics, were analyzed.

An analysis of the additive effects of family financial conditions indicates that with higher other net family income a household work status was more likely than employment among the women aged 45-64, whereas unemployment and retirement statuses were less likely only among the women aged 55-64. With higher family liabilities all non-employment statuses were less likely in relation to employment.

It appeared that a larger number of children living at home relates to less likely non-employment statuses of women in relation to employment, although all the effects were not statistically significant. Among the women aged 45-54 retirement was declining most rapidly with a larger number of children. Among the women aged 5564 household work was the least likely status when children were present. Instead with a larger number of children retirement among those aged 55-64 was a very unlikely status in relation to employment.

The older the husband was compared to the wife, the less likely were both unemployment and retirement statuses, whereas household work was more likely than employment only among the women aged 55-64.

Generally, a non-employment status of the husband was related to more likely nonemployment statuses of the woman in relation to an employment status. Among the women aged 45-54 the likelihood of being unemployed was most markedly associated, first of all, with unemployment, and next, with the husband's retirement on unemployment pension. Among the women aged 55-64 an unemployment status was most likely if the husband was retired on unemployment pension. A more likely household work status of women aged 55-64 was associated with all non-employment statuses of the husband, most markedly with the retirement status of the husband. Among the younger women aged 45-54 this effect was not significant. The retirement status of the women was most clearly associated with the retirement status of the husband, and among those aged 55-64 also with the other non-employment statuses.

Excluding the family financial variables from the analysis and comparing the results of Model 2 to the main model (Model 1) showed weakening effects of the number of children and the labor force status of the husband on unemployment and retirement statuses in relation to employment. A household work status in relation to employment was less likely with a larger number of children only when family financial variables were controlled for. Similarly, in the main model (Model 1) the effects of family financial conditions were less marked than in the models in which the number of children (Model 4) and the labor force status of the husband (Model 5) were dropped out. The likelihood of household work was an exception suggesting a stronger likelihood in relation to employment.

The results indicate that the effect of the husband's labor force status on an unemployment and a retirement status were partly related to family financial variables and vice versa, but the effects were still rather significant when all the variables were simultaneously controlled for. The effects of the number of children and current family 
financial conditions on the likelihood of household work were more independent of each other.

The more detailed results from the interaction effects between other net family income and the labor force status of the husband (Table 1) showed a declining family income effect on the likelihood of women aged 45-54 being unemployed, if the husband was unemployed (not significant); while among the women aged 55-64 the effect declined if the husband was retired, but conversely increased if the husband was unemployed. More straightforwardly results concerned retirement and especially the household work statuses of women, which are assumed to be based on individual decisions concerning labor force behavior more than the unemployment status. Concerning retirement status when other net family income was higher, the likelihood to be retired increased if the husband was unemployed, but declined if the husband was retired. The opposite finding arose concerning the household work status of women, where the likelihood of this status declined when other net family income was higher if the husband was unemployed (not significant) and increased if the husband was retired.

\section{Summary of results and discussion}

This article examined the labor force status of Finnish married women aged 4564 during the relatively stable macroeconomic time period of 1985 in 39 local labor

$\mathrm{T}$ a b l e 1. Interaction effects $(\beta)$ between other net family income and the labor force status of the husband for married women aged 45-64 in the multinomial logit models (employed is the reference category, standard errors are in the parentheses)

$\begin{array}{lccc}\text { AGED 45-54 } & \text { Unemployed } & \text { Household work } & \text { Retired } \\ \text { Intercept } & -3.100 & -4.640 & -1.219 \\ \text { Other net family income (logarithm) } & & & \\ \text { X The labor force status of the husband } & & & \\ \text { Employed\# } & 0.19 & -0.04 & 0.17 \\ \text { Unemployed } & -0.14 & (.130) & 0.31^{* * *} \\ & (.074) & 0.24^{* *} & -0.16^{* *} \\ \text { Retired } & -0.06 & (.098) & (.066) \\ & (.078) & -0.22 & -0.32^{*} \\ \text { Retired on unemployment } & 0.11 & (.208) & (.148) \\ \text { pension } & (.153) & \text { Household work } & \text { Retired } \\ \text { AGED 55-64 } & \text { Unemployed } & -5.985 & 0.419 \\ \text { Intercept } & -1.835 & & \\ \text { Other net family income (logarithm) } & & & \\ \text { X The labor force status of the husband } & & 0.14 & 0.24 \\ \text { Employed\# } & 0.18 & -0.55^{* * *} & 0.26^{* * *} \\ \text { Unemployed } & 0.32^{* * *} & (.121) & (.062) \\ & (.064) & 0.13^{*} & -0.24^{* * *} \\ \text { Retired } & -0.28^{* * *} & (.060) & (.035) \\ & (.038) & 0.28^{*} & -0.26^{* * *} \\ \text { Retired on unemployment } & -0.22^{* *} & (.117) & (.073) \\ \text { pension } & (.071) & & \end{array}$

\# reference group

${ }^{*} \mathrm{p}<.05,{ }^{* *} \mathrm{p}<.01,{ }^{* * *} \mathrm{p}<.001$

Age, eflucational level, health status, industrial sector, unemployment rate of local labor market area, net other family income, family liabilities, age difference between the spouses, the number of children and the labor force status of the husband were controlled for 
Pienta, Amy J., Jeffrey A. Burr and Jan E. Mutchler. 1994. Women's labor force participation in later life: the effects of early work and family experiences. Journal of Gerontology 49: S231-S239.

Reijo, Marie and Tapani Valkonen. 1993. Population development and the changes in the economic structure of Finnish urban areas. Yearbook of Population Research in Finland 31: 25-46.

Sammartino, Frank J. 1987. The effect of health on retirement. Social Security Bulletin 50:31-48.

SAS/STAT User's Guide. 1992. Version 6, Fourth Edition, Volume 1. Gary, NC: SAS Institute Inc.

Sweet, James A 1973. Women in the labor force. 1973. New York: Seminar Press.

Szinovacz, Maximiliane, David J. Ekerdt and Barbara H. Vinick. 1992. Families and retirement: conceptual and methodological issues. In: Families and Retirement, edited by Maximiliane Szinovacz, David J. Ekerdt and Barbara H. Vinick, pp. 1-22. Newbury Park: Sage Publications.

Weaver, David A. 1994. The work and retirement decisions of older women: a literature review. Social Security Bulletin 57: 9-24. 
Appendix

T a b l e 1. Logit effects ( $\beta$ and odds) of individual characteristics on labor force status for married women aged 45 to 54 and aged 55 to 64 in the multinomial logit models (employed is the reference category, standard errors are in the parentheses).

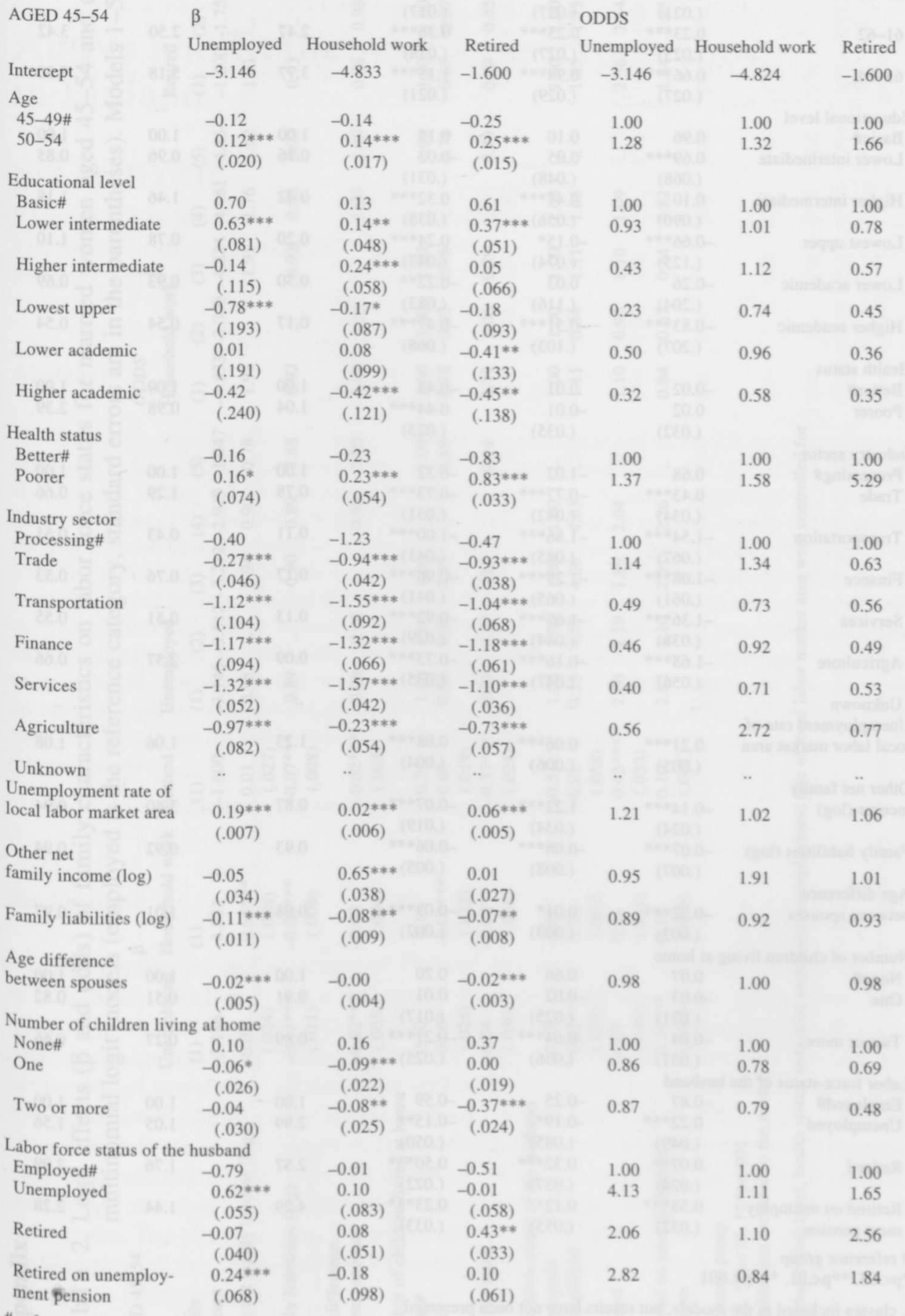

\# reference group

${ }^{*} \mathrm{p}<.05,{ }^{* *} \mathrm{p}<.01,{ }^{* * *} \mathrm{p}<.001$

.. classes included in the models, but results have not been presented 
AGED 55-64 $\quad \beta$

$\beta \quad$ ODDS

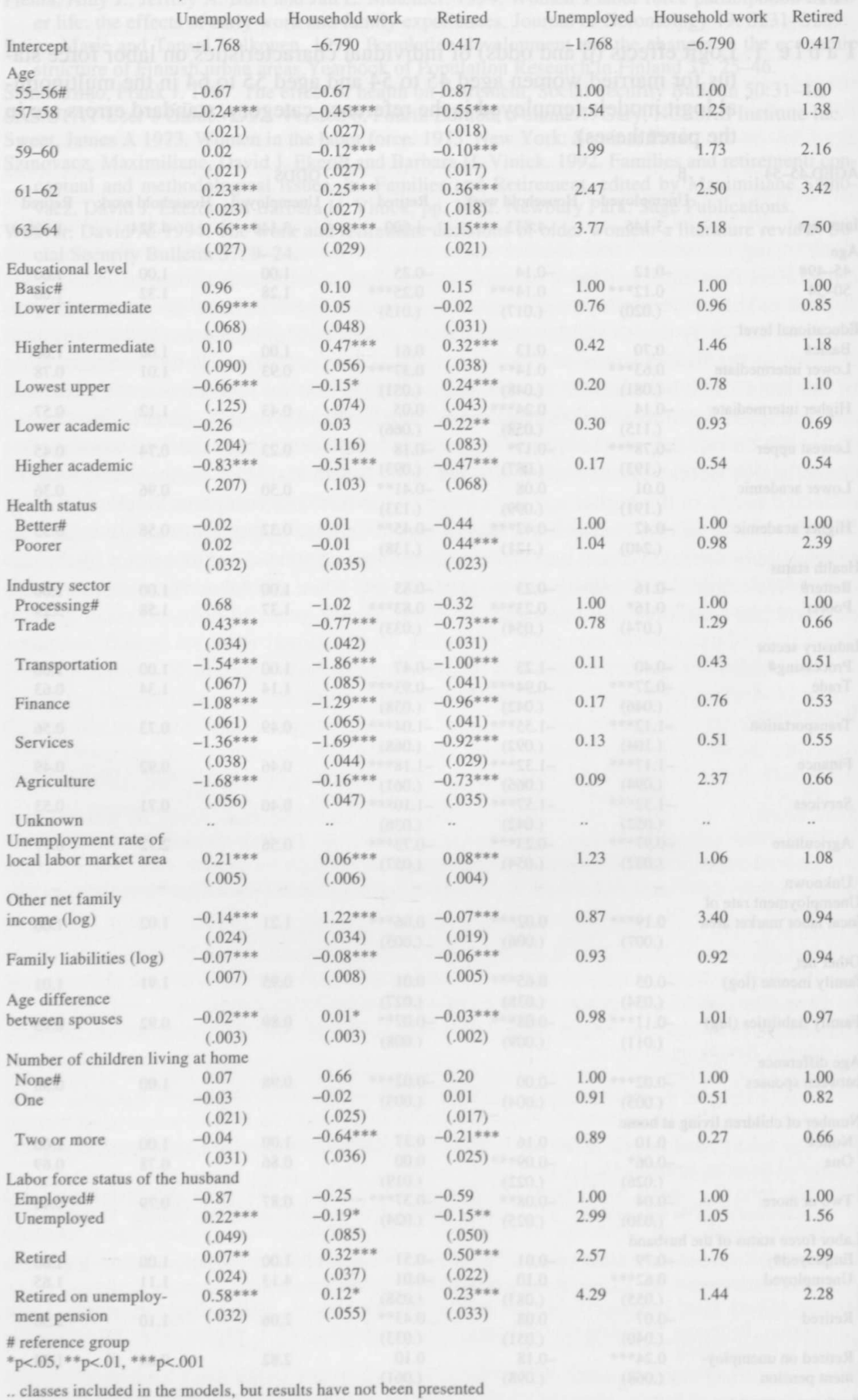




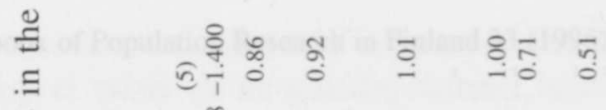

0
0
0
$n$
$n$
$n$

范

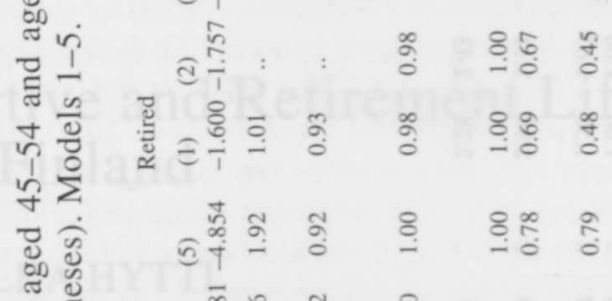

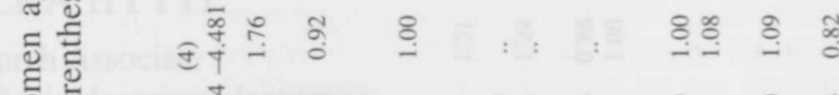

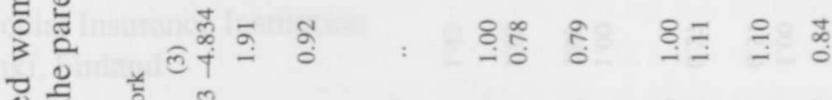

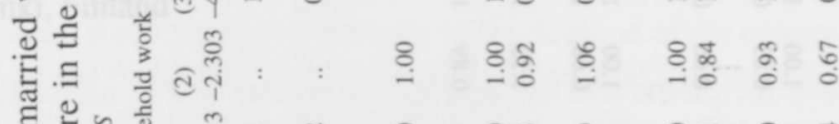

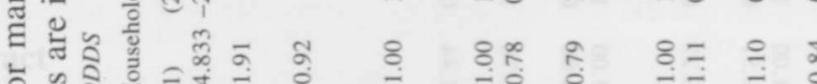

는

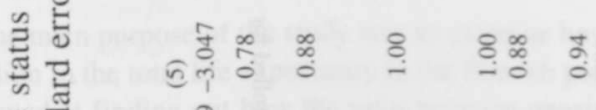

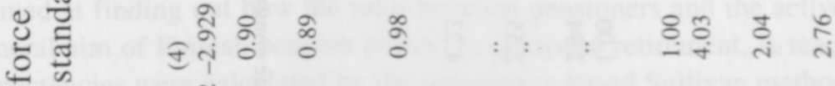

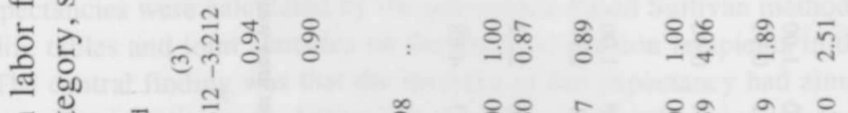

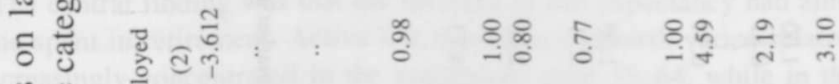

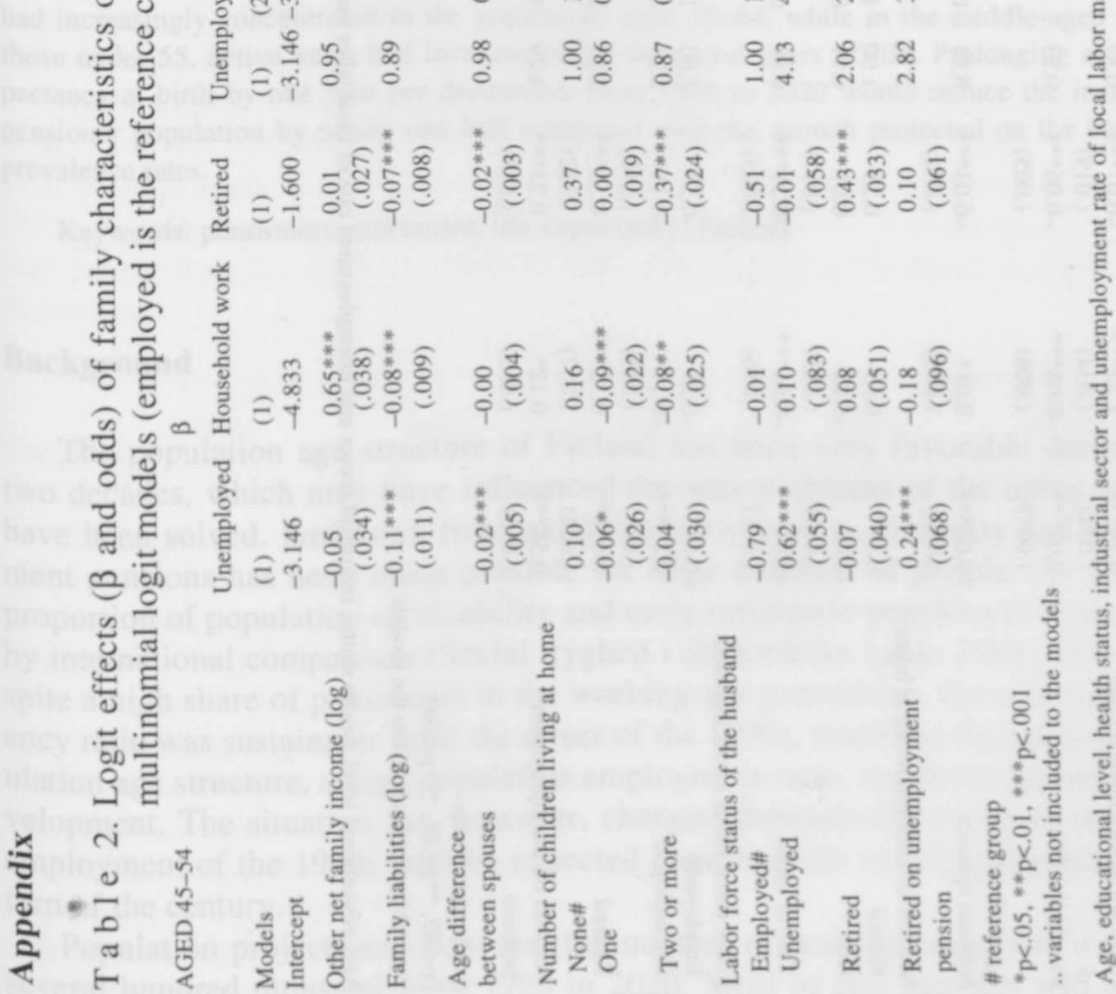

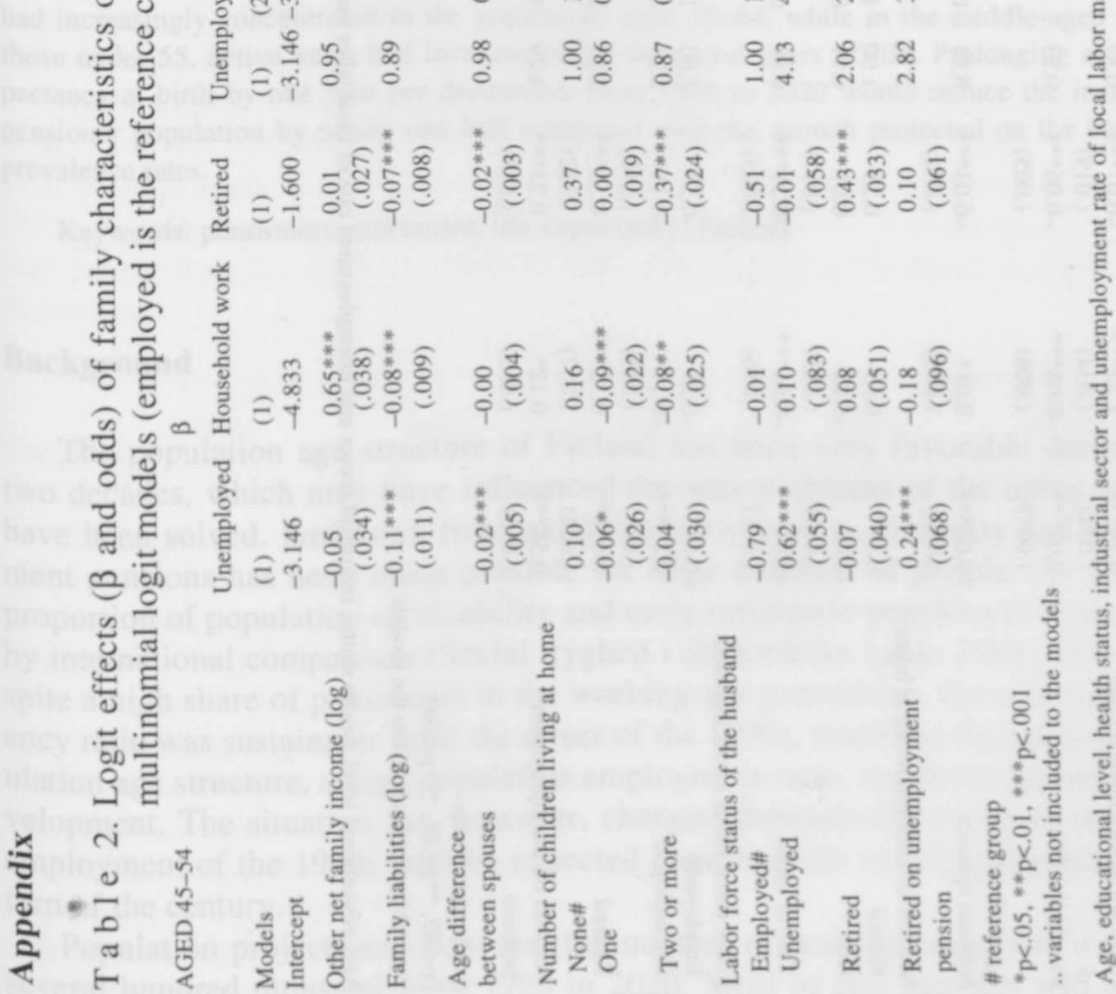

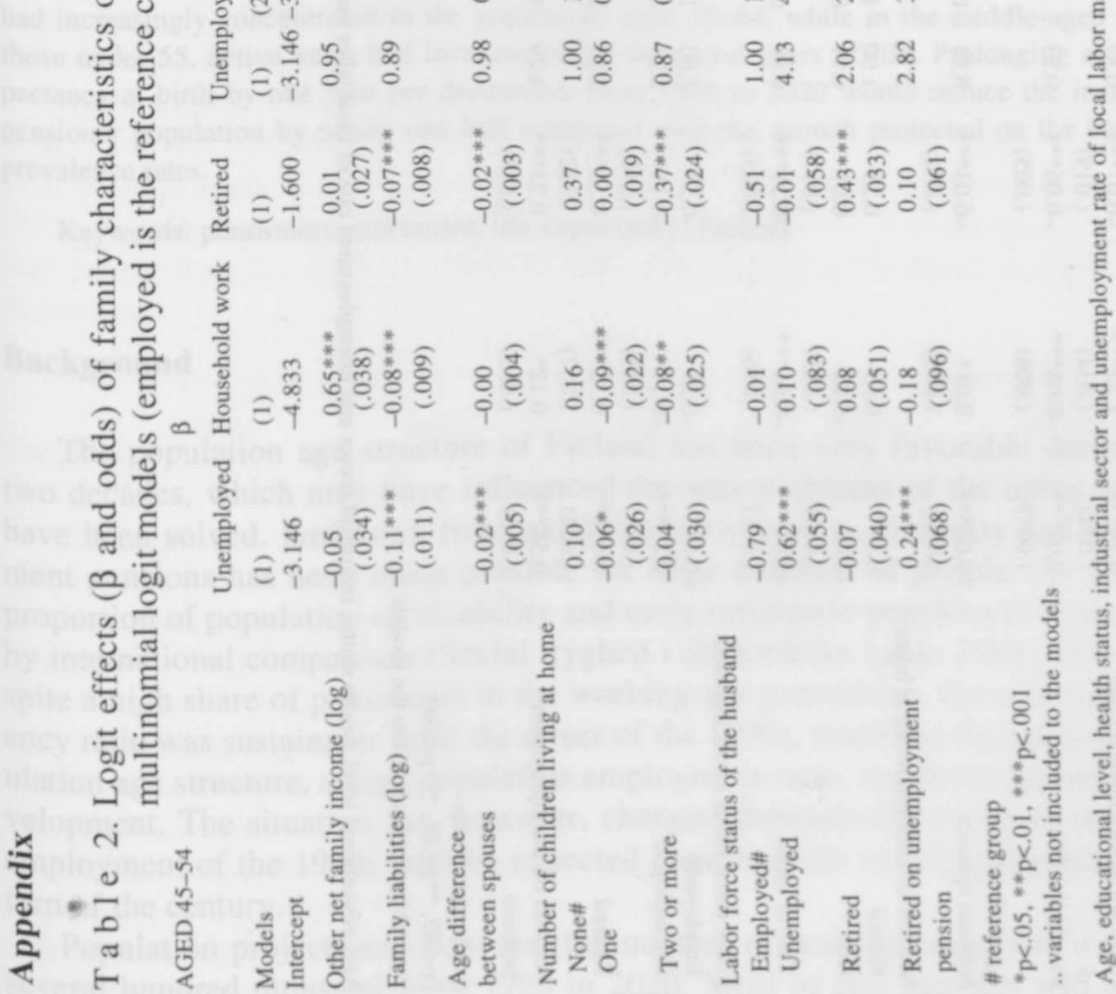

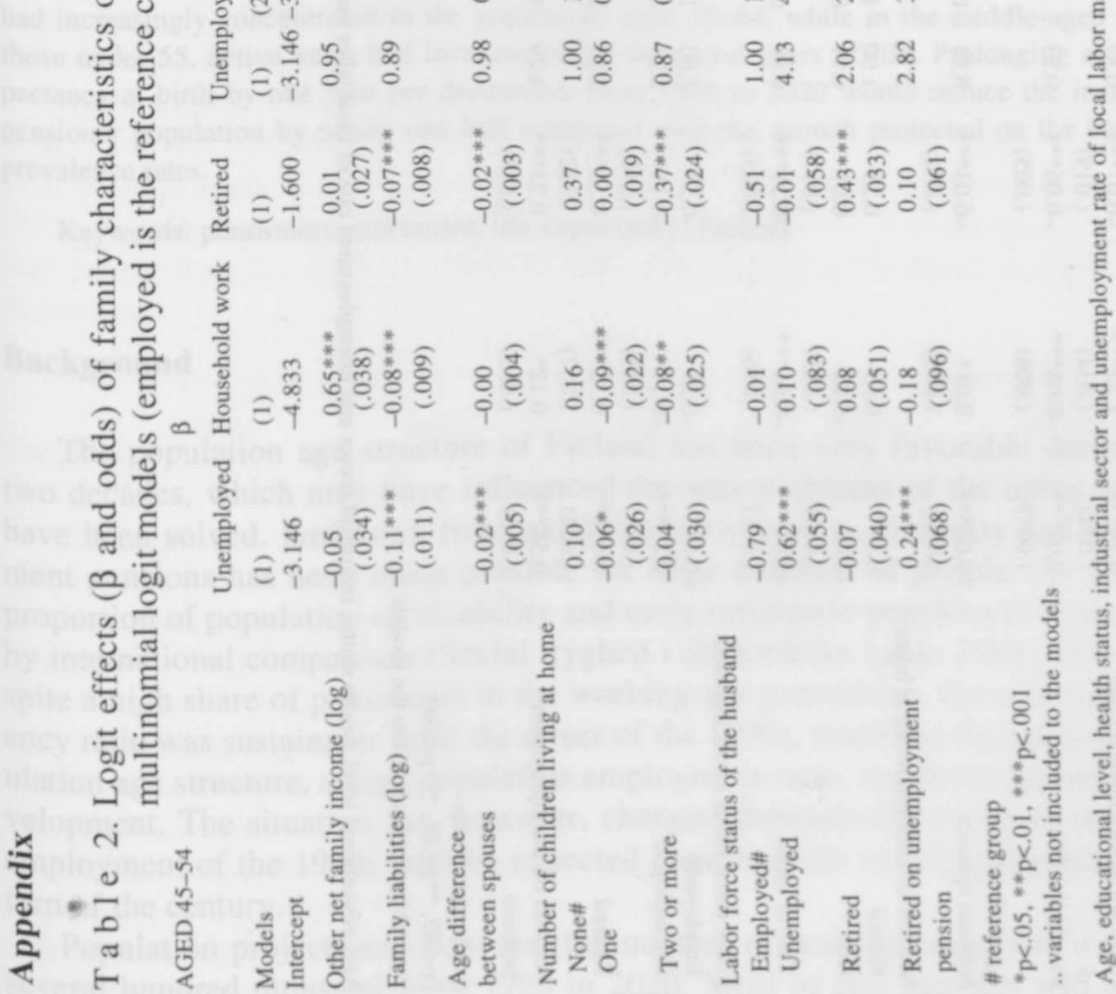

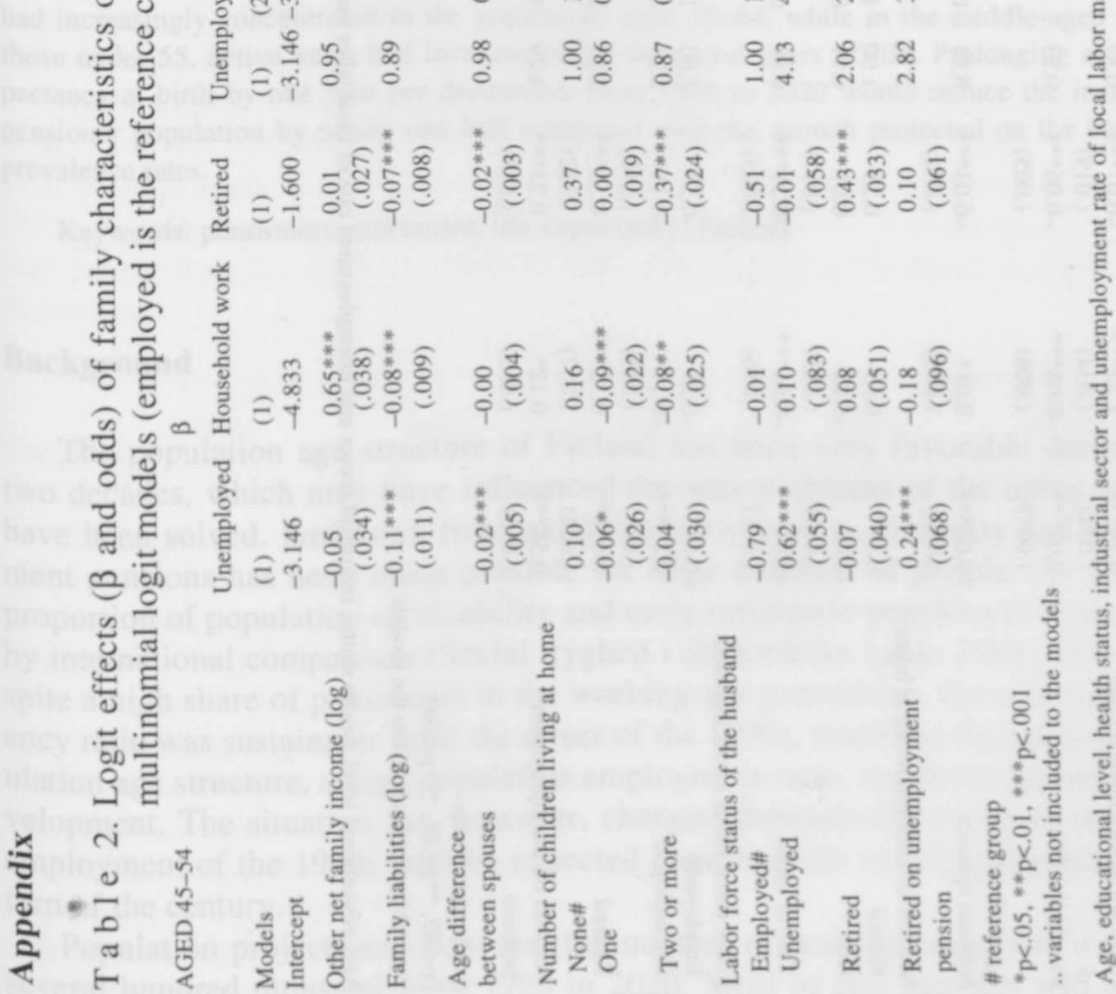

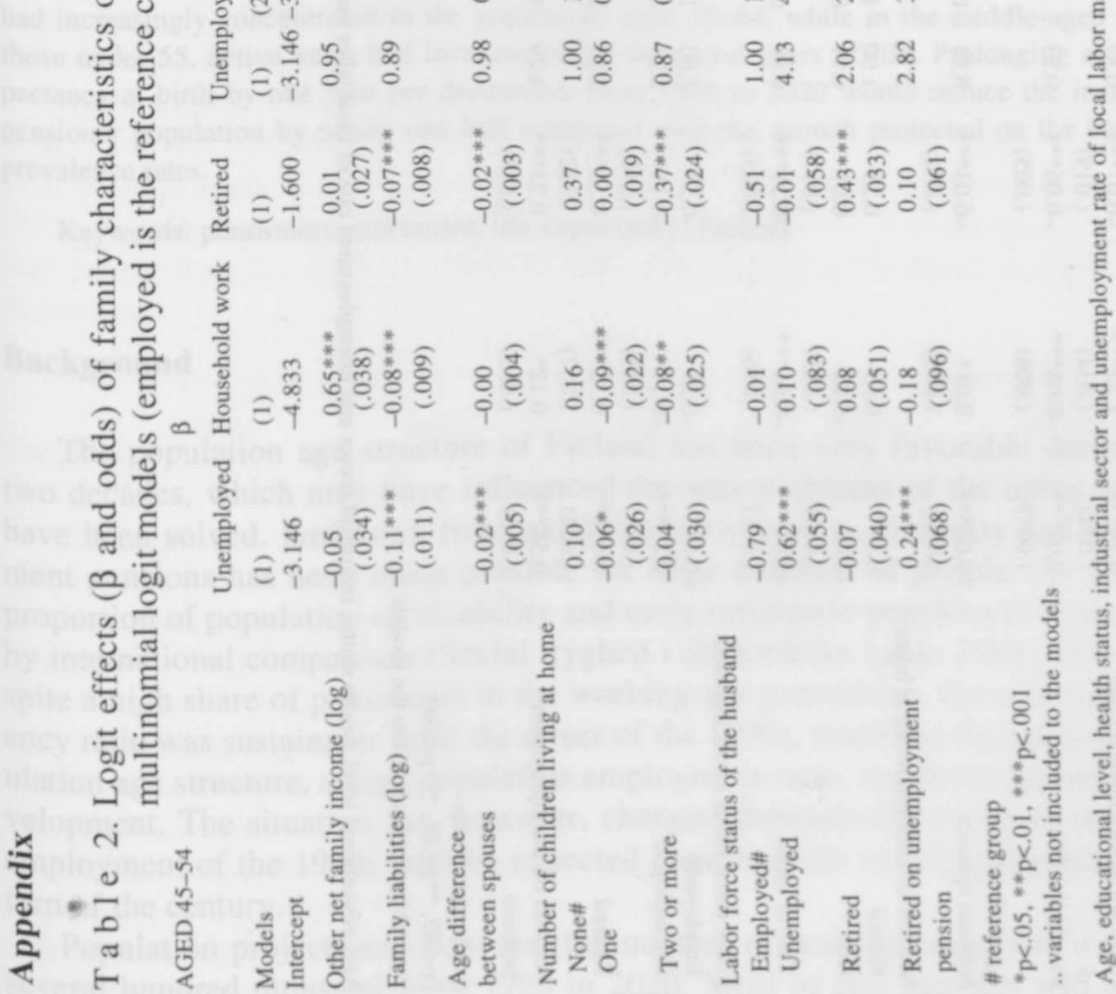




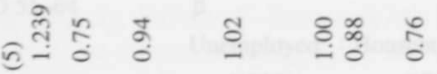

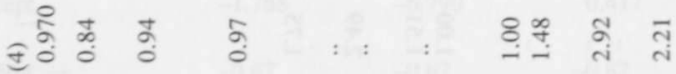

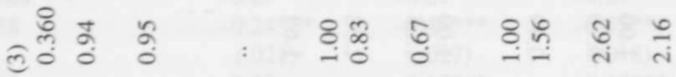

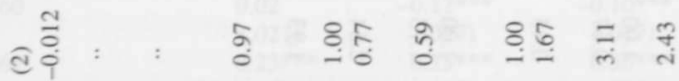

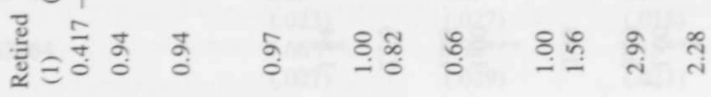

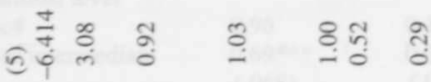

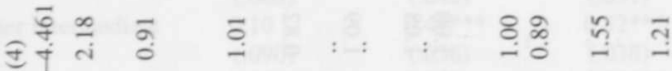

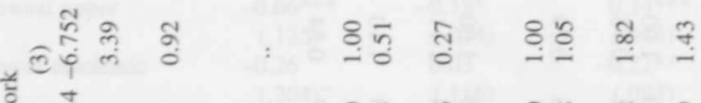

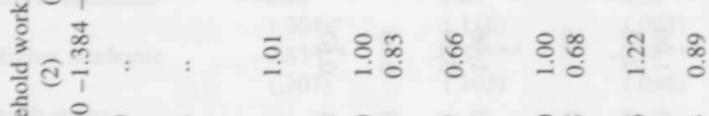

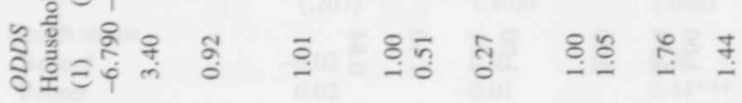

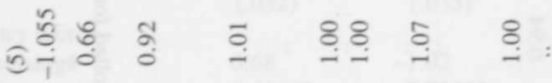

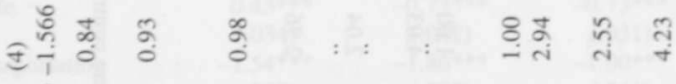

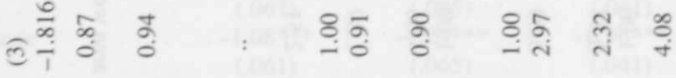

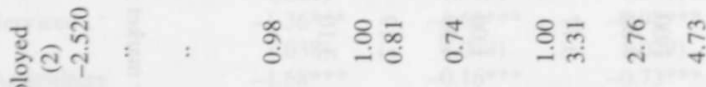

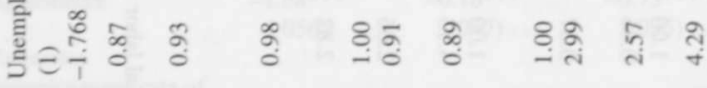

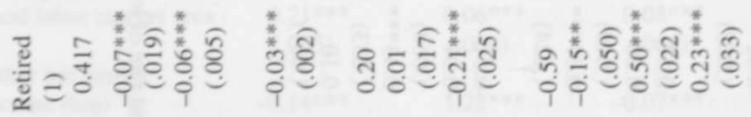

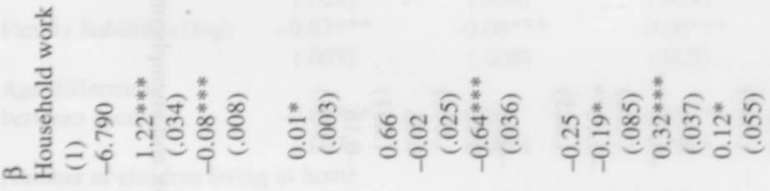

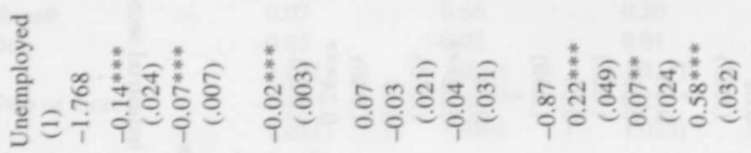

